1

Doutora em Administração pelo PROPAD/

UFPE. Atuando nos seguintes temas de pesquisa:Experiência de usuário, Apropriação tecnológica e Aprendizagem Organizacional

Professora Adjunta do Núcleo de Gestão do Centro Acadêmico do Agreste da UFPE. 2

Professor Associado e Pesquisador do Depto de Ciências Administrativas e do Mestrado em Gestão Pública da UFPE. Doutor em Linguística pelo Programa de Pós-graduação em Letras/ UFPE (com tese indicada a prêmio pela banca examinadora e publicada através de edital Propesq de Teses e Dissertações 2010). Mestre em

Administração pelo Propad/ UFPE (título obtido com distinção). Graduado em Administração pela UFPE. 3

Professora do Departamento de Administração da Universidade Federal do Espírito Santo (UFES). Doutora em Administração pelo Propad/UFPE (2014). Realizou doutorado sanduíche na Université Pierre Mendès France, no IAE Grenoble na França (2013-2014). Mestre em Psicologia pela UFPE (2008). Especialização em Planejamento e Administração de Recursos Humanos (UNICAP - 1987). Graduação em Psicologia pela Universidade Católica de Pernambuco (1985).

\section{ENTRE A DICOTOMIA PRECURSORA E AS NOVAS POSSIBILIDADES: DIVERGÊNCIAS PARADIGMÁTICAS NA GROUNDED THEORY}

\author{
BETWEEN THE PRECURSOR DICHOTOMY AND THE NEW POSSIBILITIES: \\ PARADIGMATIC DIVERGENCES IN GROUNDED THEORY
}

Daiana Amorim Ferreira ${ }^{1}$

Guilherme Lima Moura²

Vera Lúcia da Conceição Neto ${ }^{3}$
RESUMO: Considerada um marco para a pesquisa qualitativa, a metodologia Grounded Theory tem apresentado diferentes versões, desde sua proposta inicial por Glaser e Strauss (1967), seguida pelo novo enfoque dado por Strauss e Corbin (1998) e a recente visão construtivista de Charmaz (2000). Essas correntes têm notoriamente expressado partirem de pressupostos bastante divergentes, muitas vezes, inconciliáveis, já que contrapõem visões de mundo. O objetivo deste artigo é compreender as características peculiares desta metodologia que motiva estas diferentes interpretações e lhe habilita a transitar entre os paradigmas. Para alcançar o objetivo, este estudo utilizou, além da revisão da literatura acerca do tema, a análise de um corpus, construído a partir de publicações do EnEPQ (Encontro de Ensino e Pesquisa em Administração e Contabilidade). O processo de filtragem do corpus formado por 419 trabalhos apresentados no intervalo de 2007 a 2013 culminou num conjunto final de 6 artigos que fizeram uso da GT. O enquadramento epistemológico das publicações demonstrou que as posturas científicas ainda se dividem em pós-positivistas e construtivistas e outras permanecem bastante vagas ou alheias a esse aspecto.

palavras-chaves: Pesquisa em Administração, Grounded Theory, Epistemologia.

abstract: The Grounded Theory methodology has presented different versions since its initial proposal by Glaser and Strauss (1967), followed by the new approach given by Strauss and Corbin (1998) and the recent constructivist view of Charmaz (2000). These currents have notoriously expressed starting from quite divergent assumptions, often, irreconcilable, since they oppose visions of world. The purpose of this article is to understand the peculiar characteristics of this methodology that motivates these different interpretations and enables it to transit between the paradigms. In order to reach the objective, this study used a literature review on the subject and analyzed a corpus constructed from publications in the EnEPQ (Congress of Teaching and Research in Administration and Accounting). The corpus filtering process consisting of 419 papers presented between 2007 and 2013 culminated in a final set of 6 articles. The epistemological framing of those publications showed that scientific postures are still divided into post-positivists and constructivists while others remain quite vague or unrelated to this issue.

KEYwORDs: Research in Administration, Grounded Theory, Epistemology. 


\section{INTRODUÇÃO}

Reconhecidamente, a tradição científica possui um histórico quantitativo, no qual a matemática foi durante muito tempo tomada como a "rainha das ciências" e os estudos de natureza menos quantificável, em particular nas ciências sociais, eram referidos sob o rótulo pejorativo de soft science (GUBA; LINCOLN, 1994). De forma mais recente, estudos qualitativos apresentaram um forte crescimento, tal interesse pode ser atribuído ao que Flick (2004, p.17) denomina como "pluralização das esferas da vida". De fato, o contexto de pós-modernidade tem instigado pesquisas voltadas ao entendimento da complexidade dos processos sociais e culturais. A velocidade das mudanças, o caráter fragmentado e multifacetado das relações tem gerado maior demanda por significados, dimensão que está além do alcance dos números.

A pesquisa qualitativa é a tipologia convencional, porém não exclusiva, dos estudos interpretativistas e firmou-se como forma mais adequada de promover o acesso ao campo dos significados. Ressurgiu com maior intensidade a partir de um movimento reformista de cunho intelectual e crítico na academia, na década de 1970, dentro das ciências sociais, em resposta à insatisfação com os métodos experimentais e estatísticos (SCHWANDT, 1994). A preocupação da comunidade científica era desenvolver estratégias de investigação dos fenômenos cujas orientações não visassem à explicação e/ou à generalização, privilegiando a descrição e o entendimento dos mesmos.

O pressuposto básico assumido na investigação dos fenômenos humanos reconhece a presença de uma carga de razão, liberdade e vontade inerente aos mesmos. Deste modo, é que se estabelecem os significados às coisas e às pessoas nas interações sociais. Estes fenômenos são passíveis de descrição e análise que prescindem de quantificações estatísticas (CHIZZOTTI, 2003). A inexatidão e a presença de fatores contextualmente dependentes nesses estudos representam os maiores alvos das críticas. Esses aspectos, no entanto, não significam que os modelos sejam frágeis, inconsistentes ou subjetivistas. Os métodos de pesquisa têm sido aperfeiçoados, desenvolvendo-se fortes critérios de validação e confiabilidade, que refletem o fortalecimento desse tipo de pesquisa.

Um marco nessa direção foi dado pelo desenvolvimento da metodologia Grounded Theory (GT), concebida por Glaser e Strauss (1967). Uma GT pode ser entendida como "um conjunto de hipóteses conceituais integradas e sistematicamente geradas para produzir uma teoria indutiva sobre uma área substantiva (GLASER, 2004)". Seus atributos principais são o caráter altamente estruturado e seus procedimentos de coleta e análise de dados, ao mesmo tempo, simultânea, sequencial, formando uma metodologia integrada.

Após sua proposição inicial, a GT tem apresentado diferentes versões, a saber: Glaser e Strauss (1967), Strauss e Corbin (1998) e Charmaz (2000). Essas correntes têm notoriamente expressado parti- 
rem de pressupostos bastante divergentes, muitas vezes, inconciliáveis, já que contrapõem visões de mundo. Acreditando ser bastante pertinente uma construção teórica em torno deste debate, como forma de clarificar estas perspectivas formadas, o objetivo deste artigo é compreender as características peculiares desta metodologia que motiva estas diferentes interpretações e lhe habilita a transitar entre os paradigmas. Para alcançar o objetivo, o presente estudo utilizou, além da revisão da literatura acerca do tema, a análise de um corpus, construído a partir de publicações de um dos principais fóruns para o ensino e pesquisa em administração, o EnEPQ (Encontro de Ensino e Pesquisa em Administração e Contabilidade). A intenção foi ampliar as discussões presentes nos periódicos estrangeiros, apresentando o nível do debate presente nos trabalhos voltados para a prática de pesquisa em administração no Brasil.

\section{SURGIMENTO DO MÉTODO E AS PRIMEIRAS CISÕES EPISTEMOLÓGICAS}

A Grounded Theory surgiu em um momento crítico no âmbito das ciências sociais, havendo uma grande insatisfação dos pesquisadores e intelectuais da época com os métodos tradicionais de caráter quantitativo. A proposta de um processo metodológico visando gerar uma teoria pelo caminho inverso ao convencional, ou seja, oposto ao raciocínio lógico-dedutivo, representou um marco na emancipação dos métodos qualitativos de pesquisa. Essa abordagem foi desenvolvida pelos pesquisadores Barney Glaser e Anselm Strauss em um estudo sociológico sobre experiências de morte em meio hospitalar e teve sua primeira versão publicada na obra The discovery of Grounded Theory de1967.

Este trabalho, de fato, deu impulso à "revolução qualitativa" vivenciada na década de 1970, que tratou de contestar o paradigma positivista e o predomínio da lógica hipotético-dedutiva. Para Charmaz (2000, p.511), o significado revolucionário da proposta de Glaser e Strauss se justifica por seu desafio: à divisão arbitrária entre teoria e prática; à visão de que estudo qualitativo seria uma etapa precursora para a aplicação de um método mais "rigoroso"; à crença de que os métodos qualitativos seriam impressionistas e não-sistemáticos; à separação das fases de coleta e análise de dados e , ainda; às suposições de que a pesquisa qualitativa estaria habilitada apenas a gerar estudos de caso descritivos em vez de teorias.

Como forma de se impor às críticas, o método foi edificado sob uma rigorosa coleta e análise de dados, utilizando grupos comparativos de controle. A alternância entre fases de indução e dedução e a utilização de vários grupos amostrais compõem um dos conceitos centrais da abordagem, a amostragem teórica. A mesma possibilita a coleta de dados selecionando indivíduos, grupos e subgrupos que indiquem deter conhecimento acerca da realidade a ser estudada (GLASER; STRAUSS, 1967, p.49). Esta técnica parte da concepção de que alguns 
indivíduos ou grupos possuem maior, ou melhor, informação sobre determinada categoria ou propriedade, o que favorecerá o processo de construção da mesma, permitindo a saturação, ou seja, o esgotamento das informações.

Outra estratégia essencial da GT é o emprego do método comparativo constante, que consiste na integração dos procedimentos analíticos de comparação simultaneamente ao processo de codificação na análise de dados (GLASER; STRAUSS, 1967). Seu uso auxilia no reconhecimento de padrões em certos segmentos dos dados, esses padrões são agrupados e arranjados com base nas relações que estabelecem com a teoria em construção (MERRIAM, 2009). Na obra seminal da GT, os autores descrevem quatro estágios neste método: (1) Comparação de incidentes aplicável a cada categoria; (2) Integração das categorias e suas propriedades; (3) Delimitação da teoria; e (4) Redação da teoria (GLASER; STRAUSS, 1967, p. 105).

A Figura 1 ilustra o processo contínuo de refinamento de conceitos através da interpretação iterativa dos dados - este modelo já apresenta a introdução dos novos procedimentos incluídos por Strauss e Corbin (1998), codificação axial e seletiva. Calin e Weiss (2011) representam de forma bastante sintética a trajetória desta metodologia, em que agrupamento de ideias e padrões delineia os conceitos que evoluem até convergir em uma preocupação central dos participantes (the core category). Neste processo, "pedaços" de dados são codificados para identificar elementos de interesse (que podem incluir palavras simples, incidentes, frases, interpretações, etc.). Estes "pedaços" são, então, comparados entre si pelo método comparativo constante. A codificação aberta identificam as possíveis correlações de interesse nas etapas iniciais. Os conceitos levantados buscam elementos dentro dos dados que suportam ou refutam as relações hipotéticas emergentes sobre as dinâmicas identificadas no fenômeno em estudo. Na fase avançada, "pedaços" adicionais de dados são procurados para testar ainda mais estas relações emergentes no processo de amostragem teórica. Ao final, as categorias testadas integram a teoria (BLACK, 2009).

A teoria resultante é enquadrada como do tipo substantiva, que difere de uma teoria formal por apresentar um escopo mais restrito e não visar à generalização. Uma teoria substantiva explica uma realidade construída e válida para um grupo social delimitado, desse modo a explicação fornecida não se pretende absoluta (BANDEIRA-MELO; CUNHA, 2010). As teorias substantivas, em geral, estão relacionadas de modo específico às situações e suas implicações práticas (MERRIAM, 2009). 
FIGURA 1 Processo Metodológico da Grounded Theory

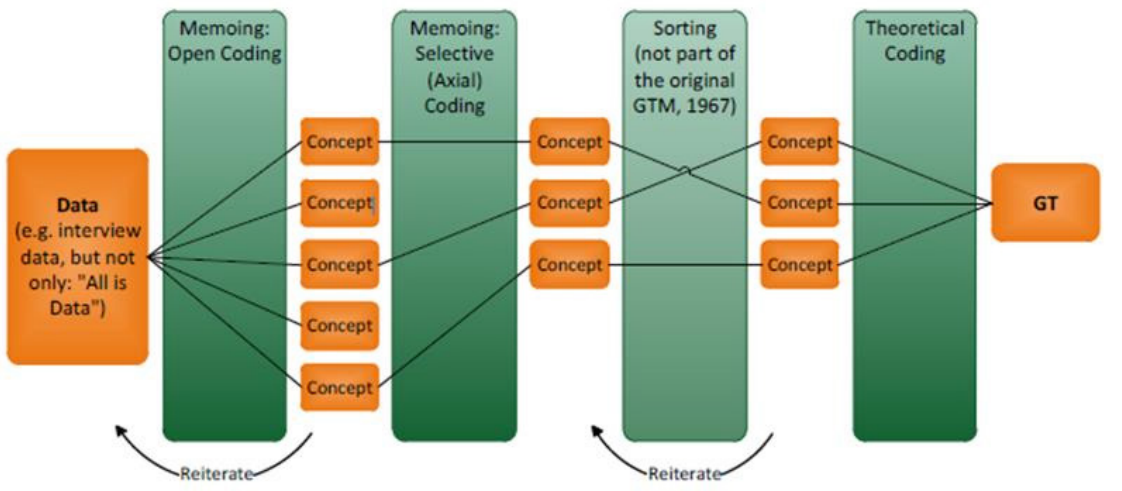

FONTE: Calin e Weiss (2011, p.2)

A colaboração entre Glaser e Strauss, apesar de bastante intensa e significativa, não foi muito duradoura. Pouco foi acrescentado ao modelo original ao longo do tempo, somente alguns anos mais tarde, Strauss desenvolveu alguns aspectos da GT com a colaboração de Juliet Corbin. O modelo apresentando pelos autores se distanciava sem, contudo, romper com os princípios e procedimentos originais do método. Essa sutil divergência assenta-se, sobretudo em dois aspectos principais, conforme Bandeira-Melo e Cunha (2010, p. 244): “é mais prescritiva, ao sugerir uma série de procedimentos, técnicas e uma formatação mais estruturada para a teoria gerada e; é mais específica na delimitação da pesquisa".

Esses novos elementos foram sendo adicionados pelas publicações de Qualitative analysis for social scientists (1987) e pelas duas edições de Basic of qualitative research (1990;1998). Na parceria Strauss e Corbin (1998), foi dada maior ênfase aos métodos, os autores focaram seus esforços em empreender algo como um detalhado manual das práticas da GT, dedicando atenção às ferramentas, às etapas de codificação (aberta, axial, seletiva, matricial), à construção dos memorandos e de notas. Bryant (2009) compara a abordagem utilizada por eles a de um livro de receitas, em face ao seu apelo prescritivo, criticando ainda que pouco fora acrescentado sobre outros aspectos mais relevantes como o papel do pesquisador ou dos participantes.

Glaser (1992) fez críticas contundentes e considerou que a versão de Strauss e Corbin fugia ao princípio básico da "emersão". Para o autor, a teoria deveria emergir dos dados, por isso as estratégias de delimitação da investigação, como por exemplo, o uso de questões mais específicas, feria a "neutralidade" da pesquisa (BANDEIRAMELO; CUNHA, 2010). A GT de Strauss e Corbin contrariou a visão de Glaser justamente por ampliar o caráter hermenêutico do pesquisador, destacando formas de ser chegar mais "precisamente" às vozes dos participantes, porém em suas obras não há discussão evidente sobre o posicionamento ontológico e epistemológico adotado (MILLS et al, 2006). Contudo, entende-se que a cisão entre o pensamento dos fundadores do método teve origem em divergências paradigmáticas. A 
seção seguinte busca apresentar esses elementos que embora implícitos permeiam os argumentos apresentados nas diversas publicações de ambos os autores e demais estudiosos da área, como também encontra suporte nas referências teóricas do método.

\section{AVALIANDO AS PERSPECTIVAS OBJETIVISTAS E SUBJETIVISTAS DA GT}

O "combate teórico" iniciado com Glaser e Strauss gerou e têm gerado muitas discussões e controvérsias acadêmicas quanto à natureza paradigmática deste método. A versão reformulada por Strauss e Corbin foi repudiada por Glaser. Modelos processuais e questões preconcebidas foram então compreendidas como uma maneira de "forçar" os dados, que segundo a versão glaseriana surgem apenas com o uso da comparação sistemática. O pensamento de Glaser reflete uma visão de mundo objetivista, em que os dados são extraídos de uma realidade externa e concreta. Cabendo ao pesquisador acessar a realidade sem conceitos ou pressuposições para alcançar a verdade de seus participantes (CHARMAZ, 2000).

Principal tese de Glaser em defesa da GT clássica se baseia na questão da emergência em seu sentido estrito, o que incluiria ignorar a literatura sobre a área substantiva como medida crucial de não "contaminar" a emergência das categorias. A despeito da sofisticação do método, esta forma de se conceber o empirismo remonta ao pensamento dos primeiros filósofos das ciências naturais a exemplo de Francis Bacon e John Locke, que defendiam a posição de que era possível realizar a generalização pela simples observação de um fenômeno, mantendo-se destituído de qualquer preconcepção teórica. Esse modo de compreender a relação entre investigador e objeto é, portanto, característica de uma epistemologia positivista (KELLE, 2005, p.37).

Do ponto de vista ontológico, o paradigma positivista entende que há uma realidade apreensível e, portanto a investigação pode alcançar o verdadeiro estado das coisas. A epistemologia é caracterizada como dualista e objetivista, isto é, pesquisador e objeto de estudo são independentes (GUBA; LINCOLN, 1994). A visão de mundo defendida por Glaser expõe sua postura positivista tradicional, ou ingênua, em relação a GT. Muitos traços presentes na abordagem original (GLASER; STRAUSS, 1967) corroboram com a concepção glaseriana, a exemplo da terminologia empregada (amostragem teórica, coleta de dados, testes), da própria ideia de emergência e de uma investigação em aberto ao trabalho empírico. Outros traços se mostram obscuros como a utilização de insights (GLASER; STRAUSS, 1967, p. 251-257) pelo pesquisador, ou então a forma flexível de utilização dos dados (IDEM, p. 161-185), entre outros que sugerem um exercício interpretativo.

Um dos pontos de maior ambiguidade está relacionado ao conceito de sensibilidade teórica. O termo aparece em Glaser e Strauss (1967) para se referir à capacidade do pesquisador para "ver dados relevantes", ou seja, a pensar através dos dados empíricos com a aju- 
da de conceitos teóricos. Enxergar o que é relevante indica tanto uma habilidade como também uma tarefa do pesquisador, que deve estabelecer as conexões entre palavras, atos e contextos dos participantes. Enquanto Glaser (1992) ainda sustenta que se deva ingressar ao campo sem ideias preconcebidas, estando dessa forma "sensibilizado" para o que os dados vão revelar - como se houvesse uma entidade chamada "dado" (MILLS et al, 2006, p.5). Por outro lado, Strauss e Corbin (1998) já passam a aconselhar o uso de uma variedade de técnicas para estimular essa sensibilidade no processo de análise. Na perspectiva destes últimos, os significados formados com os dados recebem um tratamento mais evoluído, passam a estar também vinculados à reflexividade do pesquisador. O tratamento da literatura, ao invés de ser evitado e desencorajado, constitui outra voz com qual o pesquisador pode questionar as propriedades e dimensões de seus dados com exemplos similares já registrados.

Charmaz (2000) caracteriza A GT de Strauss e Corbin como pós-positivista, destacando seu caráter prescritivo. A postura pós-positivista adota um realismo crítico e embora assuma uma realidade objetiva externa, reconhece a incapacidade de sua total apreensão (GUBA; LINCOLN, 1994). Por detalhar e sistematizar os métodos, delimitando a pesquisa a priori, Strauss e Corbin sugerem reconhecer essa falibilidade em capturar a realidade. Para Mills et al (2006, p.3) a linguagem empregada por estes autores revela uma mistura de pós-positivismo e construtivismo, ao empregarem termos de difícil conciliação como "reconhecendo as sugestões" e "mantendo a objetividade". O que se observa é que aos poucos a metodologia passa a ampliar a atividade hermenêutica do pesquisador.

A natureza da divergência entre a GT glaseriana e straussiana parte então de uma dicotomia entre objetividade e subjetividade. Eis o impasse apresentado: Se a teoria está "fundamentada" nos dados deve se manter neutra do viés do pesquisador? No entanto, fica evidente que as sugestões são necessárias e inevitáveis e cumprem seu papel para a condução do estudo. Para Bandeira-Melo e Cunha (2010), a GT situa-se em posição intermediária entre subjetivismo e objetivismo, com base no modelo construído por Morgan e Smircich (1980). O Quadro 1 apresenta uma escala entre essas duas perspectivas nas ciências sociais. 
QUADRO 1 - Pressupostos do objetivismo e subjetivismo em ciências sociais

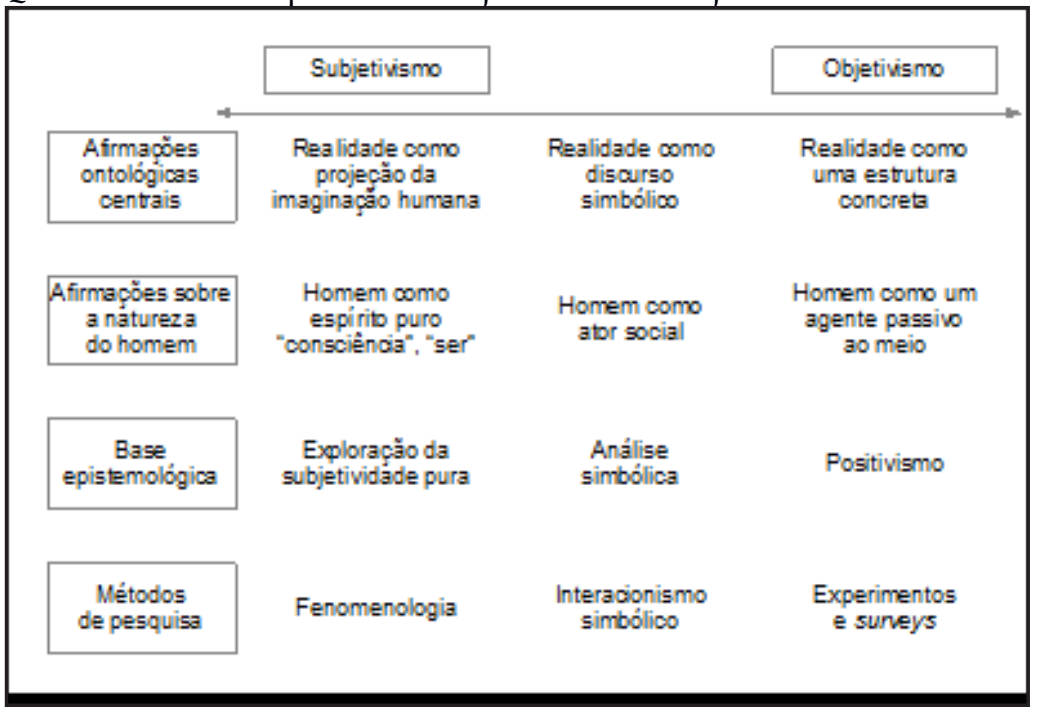

FONTE: Bandeira-Melo e Cunha (2010, p.245) adaptado de Morgan e Smircich (1980)

A GT apresenta uma abordagem peculiar, pois difere do extremo subjetivismo em que as experiências subjetivas são mais importantes que a interpretação do pesquisador. Nesta abordagem, espera-se que o pesquisador interprete os dados, fornecendo uma explicação sobre o comportamento coletivo. Essa interpretação é garantida pelo uso de diversas fontes como entrevistas, observação, documentos, não se limitando apenas a perspectiva dos participantes (BANDEIRA-MELO; CUNHA, 2010).

A análise simbólica é, de fato, a chave para compreender a essência do método, pois consiste em sua estratégia básica para acessar os significados produzidos pelos grupos. A seção seguinte aborda as raízes conceituais que embasam a GT, seu choque com a concepção empirista-indutiva, tratando também da particularidade de sua lógica inferencial.

\section{A INFLUÊNCIA DO PRAGMATISMO E DO INTERACIONISMO SIMBÓLICO}

Anselm Strauss teve uma sólida formação na Escola de Sociologia de Chicago, berço das tradições filosóficas do interacionismo simbólico e do pragmatismo norte-americano. Bryant (2009) destaca duas figuras centrais que provavelmente influenciaram a contribuição dada por Strauss para a metodologia GT: George H. Mead (1863-1931.) e John Dewey (1859-1952). Mead e Dewey pertenceram à mesma corrente filosófica conhecida como pragmatismo, os dois conviveram na Universidade de Chicago e suas obras se complementam em muitos aspectos, não apresentando, enquanto pragmatistas, oposições significativas, sobretudo na compreensão de que os seres humanos são mais bem compreendidos em relação ao seu ambiente (NELSON, 1998). Para os pragmatistas, o conhecimento existe na forma de afirmações ou teo- 
rias as quais são vistas como instrumentos ou ferramentas (BRYANT, 2009), por isso, é também comum o uso da expressão instrumentalismo. Na epígrafe de Strauss e Corbin (1998), há uma citação de Dewey extraída do livro Art as experience (1934), o mesmo autor também é mencionado na introdução do último livro de Strauss (Continual permutations of action, 1993) como influência de seu desenvolvimento intelectual.

A perspectiva conhecida como interacionismo simbólico é definida por Maines (1997, p.2) como "uma versão sociológica do pragmatismo, centrada na comunicação humana e suas consequências". Assim do mesmo modo que, para os pragmáticos, as teorias necessitam de uma "aprovação empírica", o interacionismo também se configura como uma teoria da ação. O interacionista entende que o estudo adequado de coletividades humanas se dá pelo estudo da atividade humana. A análise simbólica se concentra na atuação coletiva para investigar os fenômenos sociais, culturais e emocionais.

A diferença é uma questão de estar ontologicamente correto: estruturas, necessidades emocionais, e todos os imperativos culturais existem, mas eles só existem como formas de atividade humana. Em outras palavras, as estruturas não "agem"; e sim, as pessoas agem e alguns aspectos de sua atividade reproduzem as próprias estruturas em que as suas atividades têm lugar (Blumer, 1962). Esta é uma posição muito defendia pelos pragmáticos, pelo menos, desde o famoso ensaio de John Dewey (1896) sobre o arco reflexivo, e que mais recentemente tem sido expressa por Giddens (1984) como teoria da estruturação (MAINES, 1997, p.3).

Em linhas gerais, o interacionismo simbólico pode ser definido como o processo de interação na formação de significados para os indivíduos. Esta abordagem sociológica foi proposta por Herbert Blumer, um discípulo de Mead, sendo o primeiro responsável pela propagação e desenvolvimento das principais ideias de seu mentor (NELSON, 1998). Schwandt (1994, p. 124) comenta brevemente sobre os três princípios fundamentais definidos no modelo Mead-Blumer. São estes: o significado, a linguagem e o pensamento. O primeiro entende que os seres humanos agem em relação às pessoas e às coisas com base nos significados que eles atribuem às mesmas. Em segundo lugar, está a faculdade da linguagem que oferece meios para negociar seus significados por meio de símbolos. O pensamento, por sua vez, é o princípio que modifica a interpretação dos símbolos de indivíduo para indivíduo.

A influência dessas correntes na proposição metodológica da GT aparece de duas formas. Primeiro, pela rejeição à ideia de que a verdade científica reflete uma realidade externa independente, ao afirmar que esta resulta tanto do ato de observação e de um consenso emergente dentro de uma comunidade de observadores. Em segundo lugar, pela ênfase ao simbólico e o caráter social do pensamento e do comportamento humano, contrária às posições mais objetivistas como 
a behaviorista cujo foco são as manifestações a estímulos externos. A proposta fundamental da GT é colocar o processo interpretativo através do qual os indivíduos apreendem uma realidade subjetiva no centro da investigação científica social (BLACK, 2009).

É importante, a essa altura, considerar que essas bases teóricas podem subsidiar em boa parte a compreensão da cisão entre os fundadores da GT. Ao unir os pressupostos filosóficos do pragmatismo e do interacionismo simbólico de Strauss às concepções epistemológicas de Glaser e seu vasto conhecimento (dos termos metodológicos, da lógica indutiva e sua capacidade em conceber um modelo sistemático), a GT empreendeu uma tentativa de desenvolver um método que desfrutasse do mesmo rigor científico que as abordagens quantitativas tradicionais da época. Essa mistura acarretou na ambiguidade de suas estratégias, que consistem em combinar princípios empíricos inspirados nas ciências naturais para analisar processos interativos, que se manifestam da intersubjetividade dos indivíduos.

Esse empirismo e indutivismo ingênuo, presente na versão clássica e sustentada até hoje nas publicações de Glaser (ver o periódico editorado pelo autor no sítio groundedtheoryreview.com), é uma posição epistemológica de pouca sustentação basicamente desde as críticas feitas por Immanuel Kant. Cultivar o pensamento de que se pode se aproximar de uma realidade tal como ela é consiste em uma postura que não desfruta de boa reputação na epistemologia contemporânea. No caso da GT, além disso, une-se a inviabilidade de uma estratégia de uma mente aberta, que se sugere vazia, à dificuldade de manipular os dados para que emerjam as categorias. Uma evidência dessa complexidade é que o processo de codificação aberta pode torna-se extremamente longo e cansativo, principalmente na versão linha-a-linha. Demonstra, assim, o papel importante do conhecimento teórico para que se estimule a reflexão (KELLE, 2005).

Para Reichertz (2010), Strauss e Corbin dão pistas sobre essa questão de construção ou reconstrução realizada pelo pesquisador em face aos dados. Analisando a vertente straussiana de GT, aquele autor propõe que a lógica inferencial da GT é abdutiva e não indutiva como tradicionalmente se acredita. Sua tese contribui para uma melhor compreensão da construção empírica da GT. Assim, a controvérsia GlaserStrauss pode ser caracterizada, pelo menos em parte, como entre a indução e abdução.

A abdução é uma lógica inferencial adotada por Charles Pierce, um dos principais nomes no pragmatismo norte-americano. Por meio dela uma conclusão mais ampla pode ser alcançada com base em certos dados. A inferência é definida por conter a melhor explicação para os dados, isto é, oferecem uma ordem na qual os dados se encaixam $\mathrm{O}$ que se tem logicamente não é uma função de verdade, mas antes uma relação de causalidade. O mais importante é obter uma explicação que resolva os problemas práticos, mesmo que provisoriamente. A inferência abdutiva não é, portanto, um modo de raciocínio que proporciona 
novos conhecimentos, e nem é um método exato que auxilia na geração de hipóteses logicamente ordenadas (e, portanto, operacionalizáveis) ou alguma nova teoria. Inferência abdutiva é, sim, uma atitude em relação a dados de e para o próprio conhecimento (REICHERTZ, 2010).

A descoberta de uma ordem abdutiva, por conseguinte, não é um reflexo (puro) da realidade, nem reduz a realidade aos seus componentes mais importantes. Em vez disso, as encomendas obtidas são construções mentais com que se pode viver confortavelmente ou menos confortavelmente. Abdução é algo que todos nós fazemos, quando há uma crise ou quando não sabemos o que fazer a seguir. Para muitos fins, as construções particulares são de uso, e para outros fins, diferentes construções são úteis. Por esta razão, a busca de ordem nunca é definitivamente concluída e é sempre realizado provisoriamente. Enquanto a nova ordem é útil na realização de uma tarefa que é permitido permanecer em vigor: se o valor é limitado, as distinções devem ser feitas e, se ele se mostra inútil, ele é abandonado. Neste sentido, as ordens abdutivamente descobertos não são nem (preferencial), nem construções (válidos) reconstruções, mas utilizável (re) construções.

Ao se relacionar alguns conceitos da GT já explanados ao longo deste ensaio, tais como a noção de teoria substantiva, a sensibilidade teórica e a concepção pragmática, notar-se-á que seu processo metodológico realiza a reconstrução dos dados, oferecendo por meio de seu refinamento/seleção uma explicação que esteja coerente a esses dados (ver os critérios de validade da teoria - fit, relevance, workability e modifiability). Delinea-se, dessa forma, o exercício interpretativo daquele que realiza essa reconstrução, demonstrando como se dá a influência desses dois elementos implícitos, a lógica abdutiva e, por conseguinte, a hermenêutica.

Para Reichertz (2010), o modelo original já apresentava esses elementos, e ao serem desenvolvidos por Strauss, levou a divergência de seus co-criadores. Mills et al (2006) colocam a abordagem de Strauss e Corbin em termos de uma GT evoluída. A metáfora de uma espiral é utilizada para caracterizar as mudanças que insurgiram. Mudanças que não provocaram um rompimento de seus princípios centrais, mas aperfeiçoaram seus procedimentos, inclinando-se, de fato, para suas bases teóricas. O grande trunfo da metodologia GT está em seu potencial sistemático e a flexibilidade de sua aplicação. É em favor dos benefícios do método para os estudos qualitativos em geral que uma terceira corrente vem ganhando espaço nos debates, a GT construtivista.

\section{A PROPOSTA CONSTRUTIVISTA, PARA ALÉM DE UM MÉTODO}

Por volta da década de 1990, enquanto se avolumavam as discussões entre as versões glaseriana e straussiana, sem que se apontasse alguma expectativa de consenso quanto a um modelo acabado 
e definido de GT, uma terceira possibilidade surgiu para contrapor ambas, a GT construtivista. Proposta pela socióloga Kathy Charmaz, este novo modelo se propõe a evidenciar "as estratégias construtivistas já discerníveis em Strauss e Corbin (MILLS et al, 2006, p.3)", oferecendo uma reinterpretação sobre a natureza da relação entre pesquisador e participantes. Tal como o positivismo e o pós-positivismo, o paradigma construtivista tem seus próprios pressupostos sobre a realidade e o processo de conhecer. Nessa perspectiva entende-se que a construção do conhecimento ocorre como resultado das interações humanas, tendo a ação social como enfoque, situando-se desse modo em oposição às concepções objetivistas e essencialistas.

Construtivistas dão ênfase ao caráter pluralista e plástico da realidade - pluralista no sentido que a realidade é expressa em uma variedade de símbolos e sistemas de linguagem, e plástico no sentido em que a realidade se alonga e se molda para se ajustar aos atos propositais de agência humana intencional (SCHWANDT, 1994, p.125).

Dada suas bases, uma abordagem construtivista da GT passa a reconhecer o aspecto transacional e subjetivista entre investigador e objeto da investigação, o que significa que o conhecimento produzido não seria resultado de captura/coleta, e sim de criação (GUBA; LINCOLN, 1994). A visão construtivista de Charmaz sobre a GT refuta, portanto, as noções de emergência e objetividade defendidas pelos proponentes do método. Para a autora, apenas os dados não oferecem uma janela para a realidade, de modo que a mesma surge de um processo interativo que é temporal, cultural e contextual. As construções individuais são legitimadas e refinadas pela interação entre pesquisador e pesquisado, o que rejeita o status de objetividade dos dados, na verdade, "dados são construções narrativas, eles reconstroem a experiência, eles não são a experiência em si (CHARMAZ, 2000, p.514)".

Visto isso, esta vertente não aceita que a teoria simplesmente emerja dos dados, mas da interação do pesquisador com esses dados. A circularidade inerente ao método (fases de coleta e análise) faz com que as interpretações sejam orientadas pelos dados, e esses, por sua vez, pelas interpretações. O papel do pesquisador passa a ser central, ainda muito mais amplo do que Strauss e Corbin (1998) já sugeriam. As diretrizes presentes no Basics, com sua prescrição e didatismo, demonstravam a preocupação exatamente em refrear essa intervenção

A proposta construtivista se baseia em três argumentos: em primeiro lugar, as estratégias da GT não precisam ser rígidas ou prescritivas; em segundo, o foco no significado não demonstra limites à pesquisa, mas a necessidade de uma compreensão interpretativa; e, por fim, as estratégias da GT podem ser adotadas sem que necessariamente se abracem às tendências positivistas de seus fundadores (CHARMAZ, 2000). Na perspectiva da autora, a metodologia, permite que se vislumbre um continuum em que uma GT objetivista e outra construtivista são 
discerníveis e que podem ser optadas, conforme as crenças filosóficas sem prejuízo da qualidade de seus métodos.

Charmaz (2000, p. 522) defende a GT como um poderoso conjunto de ferramentas para entender os campos empíricos e afirma que seu uso pode ser revisto em favor de uma prática "mais aberta", propondo uma utilização mais flexível e heurística. A visão da autora é de que as pesquisas qualitativas, como a etnografia, podem beneficiar-se do rigor que o método confere. Seu modelo sistemático de análise de dados qualitativos oferece as seguintes contribuições: suas estratégias guiam o pesquisador passo a passo pelo processo de análise; a natureza auto-corretiva do processo de coleta de dados; a análise simultânea permite a descrição contextual; e a ênfase nos métodos comparativos.

Observa-se que na abordagem construtivista, as estratégias permanecem as mesmas (coleta e análise simultânea, amostragem teórica, método comparativo), o que diferencia a abordagem construtivista é o caráter da relação entre o pesquisador e pesquisado e a forma de construção dos dados. Adotar a perspectiva construtivista no desenvolvimento de uma GT corresponde a um ganho de profundidade e entendimento dos respondentes e seus mundos. Essa vertente está mais engajada na busca pelo significado, o que inclui os significados dos respondentes e dos pesquisadores. Ao estreitar a relação entre esses pólos, intenciona-se obter maior qualidade dos dados, desenvolvendo as suposições subjacentes as declarações. A busca é desdobrar o que é declarado, evidenciando as experiências (CHARMAZ, 2000).

Em Constructivist Grounded Theory?, Glaser (2002) manifesta seus argumentos contrários à versão proposta por Charmaz. Ele admite que na análise de dados ocorra a construção de dados e exista uma interpretação comum do entrevistador e do entrevistado, à medida que entrevistas prosseguem, mas que essas ocorrências representam uma parte muito ínfima da GT. É incisivo ao afirmar que “Não há tal coisa para GT como viés nos dados, ou dados subjetivos ou objetivos, ou dados mal interpretados (GLASER, 2002, p.1), seu argumento é que os dados não são construídos por interpretações interativas. Dentre outras críticas, ele acusa a autora de querer resolver o problema da precisão por meio de entrevistas em profundidade, que são um tipo de entrevista utilizada em situações muito específicas, que representam apenas uma parte da GT. Muitas das entrevistas em GT seriam mais um tipo de escuta passiva e, só mais tarde, durante as perguntas na amostragem teórica se tornam direcionadas a outros participantes com base nas categorias emergentes. Para Glaser (2002) a interferência pessoal na coleta, relatórios e codificação dos dados é inevitável, mas ocorre por uma limitação humana, não sendo adequado chamar a isso de dados construtivistas. A GT clássica, defendida pelo autor enxerga a construção com um papel muito pequeno no método como um todo, sustentando novamente a possibilidade de passividade e imparcialidade do pesquisador perante o campo empírico. 
Para Bryant (2003) os argumentos de Charmaz (2000) foram bastante claros, estabeleceram simplesmente uma distinção entre conceitos objetivistas e construtivistas da GT. O primeiro assume a realidade de um mundo externo, tomando como verdadeiro a existência de um observador neutro, e categorias vistas como derivadas dos dados. O segundo "reconhece que o observador cria os dados e a análise subsequente através da interação com o que é observado (CHARMAZ, p.523) ", não prescrevendo a visão construtivista como a única válida. O Quadro 1 apresenta uma síntese das correntes de GT discutidas ao longo deste ensaio, destacando-se os pressupostos assumidos em cada uma.

QUADRO 1 - Pressupostos das diferentes versões de GT

\begin{tabular}{|c|c|c|c|}
\hline Postura & Positivista & Pós-positivista & Construtivista \\
\hline Defensores & Glaser & Strauss e Corbin & Charmaz \\
\hline Pressupostos & $\begin{array}{l}\text { Realidade objetiva e externa; } \\
\text { Observador neutro que descobre os } \\
\text { dados; } \\
\text { Papel reduzido das questões de } \\
\text { pesquisa; } \\
\text { Obtenção objetiva dos dados. }\end{array}$ & $\begin{array}{l}\text { Assume os pressupostos do } \\
\text { positivismo (realidade externa e } \\
\text { objetiva); } \\
\text { Reconhece a intervenção do sujeito; } \\
\text { Ênfase nas técnicas e procedimentos } \\
\text { para minimizar a intervenção. }\end{array}$ & $\begin{array}{l}\text { Assume o relativismo de múltiplas } \\
\text { realidades sociais; } \\
\text { Reconhece a criação de conhecimento } \\
\text { pelo observador e observado; } \\
\text { Visa à compreensão interpretativa dos } \\
\text { significados dos sujeitos. }\end{array}$ \\
\hline
\end{tabular}

A proposta construtivista mostra-se uma alternativa que busca flexibilizar os procedimentos metodológicos para uma prática interpretativa de GT. Mostra-se coerente com os princípios teóricos que embasam o método e não contratariam, antes adaptam, suas estratégias, alinhando-a a seu objetivo que estudar os indivíduos em seus contextos naturais. A manutenção da postura positivista - de distanciamento, passividade, antisubjetiva - retira o protagonismo do pesquisador e seu potencial em desenvolver as experiências dos participantes. A GT construtivista remedia as fraquezas conceituais e põe fim as ambiguidades que a abordagem original carregava.

\section{PROCEDIMENTOS METODOLÓGICOS}

Orientada pela revisão da literatura acerca das diferentes abordagens e práticas da GT, o presente estudo buscou ampliar o debate, trazendo as perspectivas de estudos nacionais, particularmente na área de pesquisa e ensino em admi- 
nistração. Optou-se, então, pela construção de um corpus de pesquisa, tendo como base a compreensão de Bauer e Aarts (2008) de que um corpus pode ser formado a partir de um conjunto de materiais sob diversos formatos - textual, verbal, gestual, etc. (BEBER, 2004). O procedimento metodológico adotado, para este fim, foi o desk research, método no qual se realiza uma seleção de materiais secundários, advindos de determinadas fontes tais como: banco de dados, relatórios, estatísticas de organizações privadas e públicas entre outras (WESTWOOD, 2005).

No caso específico desta pesquisa, o corpus compreende o conjunto de trabalhos publicados que trataram do tema, metodologia grounded theory, nas edições do evento nacional EnEPQ (no período de 2007 a 2013), tal evento foi deliberadamente escolhido para ser alvo do estudo por tratar-se de um dos principais fóruns de discussão sobre pesquisa e ensino em administração no Brasil, tendo já ocorrido, até o momento do levantamento, um número razoável de edições.

A construção do corpus é um processo sistemático, sendo, neste caso, realizado por meio de etapas de filtragem e de análise, expostas a seguir:

- Etapa 1: Busca e download das publicações de todas as edições do evento da página eletrônica (anpad.org) para o computador. Foram ao todo 4 (quatro) encontros, sendo 2007 (com 137 trabalhos apresentados), 2009 (com 83), 2011 (com 96) e 2013 (com 103). Foi realizado o arquivamento eletrônico de todos os 419 artigos científicos, compondo assim a base de dados para a desk research.

- Etapa 2: Com auxílio de software de localização para arquivos do tipo pdf (portable document filed), a pesquisa pôde selecionar apenas os trabalhos que faziam menção ao termo grounded theory. Nesta etapa, 6 (seis) trabalhos foram identificados para a realização da etapa seguinte.

- Etapa 3: Os trabalhos foram submetidos a análise (identificação da área, abordagem e postura epistemológica) para a construção dos resultados apresentados na seção seguinte.

Após reunido o conjunto refinado de artigos publicados, o mesmo foi submetido à Análise de Conteúdo (AC), especificamente, à análise categorial que é o método das categorias que permite classificar os elementos de significação constitutivos da mensagem (BARDIN, 2004). Os resultados foram classificados e sintetizados em quadros explicativos para sua melhor compreensão.

\section{ANÁLISE DOS RESULTADOS}

Conforme abordado na seção de procedimentos metodológicos, com o objetivo de conferir maior amplitude ao debate teórico sobre as diferentes versões de GT e suas divergentes perspectivas epistemológicas, esta pesquisa realizou um levantamento acerca das discussões sobre o uso do método no âmbito da pesquisa e ensino em administração 
nos domínios nacionais. O processo de filtragem realizado no corpus formado por 419 trabalhos apresentados no evento EnEPQ (2007 a 2013) e disponíveis nos anais da página eletrônica do Encontro, resultaram na seleção de 6 artigos científicos que abordaram o uso da GT em pesquisa, no campo da administração. O Quadro 2 reúne os títulos dos trabalhos postos à análise:

\begin{tabular}{|c|}
\hline Quadro 2 - Publicações do EnPQ (2007-2013) sobre Grounded Theory \\
\hline $\begin{array}{lll}\text { Título do trabalho } & \text { Autor(s)/Ano }\end{array}$ \\
\hline $\begin{array}{l}\text { Etnografia e grounded theory na pesquisa de marketing de Lourenço et al (2007) } \\
\text { relacionamento no mercado consumidor: uma proposta metodológica }\end{array}$ \\
\hline $\begin{array}{l}\text { Não pergunte à teoria sobre estratégia o que ela pode fazer pela Santos, Tureta e Rosa (2007) } \\
\text { prática, sem se perguntar o que a prática pode fazer pela teoria sobre } \\
\text { estratégia }\end{array}$ \\
\hline $\begin{array}{l}\text { Improving Brazilian Administration Research and Practice through Predebon et al (2007) } \\
\text { Grounded Theory }\end{array}$ \\
\hline $\begin{array}{l}\text { Pesquisa qualitativa no campo da administração da produção e } \begin{array}{l}\text { Marchi, Dellagnelo e Erdmann } \\
\text { operaços: enlaces e oportunidades de aplicação }\end{array} \\
\text { (2011) }\end{array}$ \\
\hline $\begin{array}{l}\text { Abordagem qualitativa na pesquisa em administração: um olhar Araújo (2013) } \\
\text { segundo a pragmática da linguagem }\end{array}$ \\
\hline $\begin{array}{l}\text { Pesquisa-ação em sistemas de informação de } 2002 \text { a } 2012 \text { - uma Tarjara (2013) } \\
\text { revisão sistemática }\end{array}$ \\
\hline Fonte: Elaborado pelos autores (2014) \\
\hline
\end{tabular}

Uma vez selecionado o material para análise, partiu-se em busca de algumas características importantes para definição da produção científica levantada. Deste modo, reuniu-se informações sobre a área temática - sabendo-se que o campo da administração apresenta diversas subáreas (marketing, finanças, produção, etc.) - descrição breve da proposta ou discussão do artigo, assim como a definição da postura epistemológica colocada ou defendida pelos autores. A análise destes aspectos encontra-se detalhado pelo Quadro 3.

De acordo com o exposto no Quadro 3, o interesse pelo método aparece nas mais diversas áreas da administração como Produção e Sistemas de Informação, tal fato se justifica pela flexibilidade e, ao mesmo tempo, rigor dos procedimentos, e que o coloca em destaque no que se refere às metodologias qualitativas. Ao se analisar o conteúdo das propostas ou discussões, foi possível perceber, exatamente, esse caráter de "novo" e "alternativo" para as práticas metodológicas consagradas dentro de cada área. Essa defesa foi vista em Lourenço et al (2007) ao propor uma estratégia metodológica em 
que GT e etnografia são combinadas para pesquisar fenômenos no Marketing de Relacionamento (MC). No trabalho de Predebon et al (2007), essa defesa pelo maior uso do método se estende para as diversas áreas da administração, destacando-se os ganhos que podem ser obtidos, ao se sair da exclusividade das práticas metodológicas tradicionais como surveys e proposição de modelos explicativos matemáticos. Na mesma direção, também se situa a proposta de Marchi, Dellagnelo e Erdmann (2011) numa área tão marcada pela abordagem quantitativa como a de Administração da Produção e Operações.

\begin{tabular}{|c|c|c|c|}
\hline \multicolumn{4}{|c|}{ Quadro 3 - Aspectos centrais do corpus da pesquisa } \\
\hline Área temática & Ano & Proposta ou Discussão & Postura Epistemológica \\
\hline Pesquisa em Marketing & 2007 & $\begin{array}{l}\text { Uso do método GT } \\
\text { combinado ao método } \\
\text { etnográfico para estudo em } \\
\text { Marketing de Relacionamento. }\end{array}$ & $\begin{array}{l}\text { Pós-positivista - Visão } \\
\text { Strauss e Corbin }\end{array}$ \\
\hline $\begin{array}{l}\text { Pesquisa em Estratégia } \\
\text { Empresarial }\end{array}$ & 2007 & $\begin{array}{l}\text { Utilização da GT e de } \\
\text { narrativas práticas para o } \\
\text { estudo de Estratégia. }\end{array}$ & $\begin{array}{l}\text { Construtivista ou } \\
\text { Interpretativista - Visão } \\
\text { Charmaz }\end{array}$ \\
\hline $\begin{array}{l}\text { Pesquisa nas diversas } \\
\text { áreas de Administração }\end{array}$ & 2007 & $\begin{array}{l}\text { Proposta de melhoria das } \\
\text { pesquisas em Administração } \\
\text { pela utilização da GT }\end{array}$ & $\begin{array}{l}\text { Pós-positivista - Visão } \\
\text { Strauss e Corbin }\end{array}$ \\
\hline $\begin{array}{l}\text { Pesquisa em } \\
\text { Administração da } \\
\text { Produção }\end{array}$ & 2011 & $\begin{array}{l}\text { GT como possibilidade de } \\
\text { pesquisa qualitativa para a } \\
\text { Administração da Produção e } \\
\text { Operações. }\end{array}$ & $\begin{array}{l}\text { Construtivista ou } \\
\text { Interpretativista - Visão } \\
\text { Charmaz }\end{array}$ \\
\hline $\begin{array}{l}\text { Pesquisa nas diversas } \\
\text { áreas de Administração }\end{array}$ & 2013 & $\begin{array}{l}\text { GT como uma das } \\
\text { possibilidades em pesquisa } \\
\text { qualitativa para as áreas de } \\
\text { administração }\end{array}$ & Não definida \\
\hline $\begin{array}{l}\text { Pesquisa em Sistemas de } \\
\text { Informacão }\end{array}$ & 2013 & $\begin{array}{l}\text { Uso do método GT com a } \\
\text { pesquisa-ação. }\end{array}$ & Não definida \\
\hline
\end{tabular}

Todos os debates identificados, portanto, apresentaram uma visão apreciativa do método, apontando-o como uma nova via para estudos com foco em organizações e negócios. Por outro lado, essa abordagem ainda no nível do incentivo e proposição demonstra que há pouca difusão no uso da GT, havendo muito para ser explorado, para que se possa, de fato, saber-se dos reais ganhos com sua aplicação. Tal levantamento pode ser realizado numa ocasião futura, quando o método tornar-se mais disseminado nas pesquisas em administração. 
Quanto às posturas epistemológicas, o trabalho de análise teve que lidar com aspectos mais imbricados para a definição da visão dos autores dentro de um dos paradigmas identificados. Com base nas características elencadas no Quadro 1, na qual se definiu dentro de cada abordagem de GT os seus principais pressupostos. Desse modo, categorizou-se dois trabalhos dentro da visão pós-positivista presente na corrente de Strauss e Corbin (1998), uma vez que estes trouxeram descrições e conceitos peculiares nessa abordagem. Outros dois artigos apresentaram concepções que se adequaram mais a proposta construtivista de Charmaz (2000), mencionando o papel de interação entre pesquisador e participantes e o entendimento dos dados da pesquisa como resultado dessa construção mútua. As duas publicações restantes não adicionaram informação suficiente para que esta classificação pudesse ser evidenciada, foram então categorizadas como não-definidas. Notase que as visões, portanto, coexistem e não implicam, necessariamente, em exclusão. Cada pesquisador tenta acolher os conceitos e procedimentos que mais se aproximam do problema que investiga. Logo, é essa adequação que deve ser observada diante das divergências que foram apresentadas e discutidas ao longo deste artigo.

\section{CONSIDERAÇÕES FINAIS}

O surgimento da Grounded Theory significou uma grande contribuição para a pesquisa qualitativa, entendendo sua então busca por legitimidade em um contexto em que predominavam critérios de cientificidade baseados em precisão e controle. O mérito, além do impulso histórico que representou, dá-se também pela qualidade das estratégias metodológicas. O processo sistemático de análise de dados constitui ferramentas aplicáveis a diversos métodos qualitativos, nesse sentido, citam-se os estudos de caso (MERRIAM, 2009), as etnografias (CHARMAZ, 200o). Comparação constante e amostragem teórica conduzem a pesquisa com mais rigor e viabilizam a formação de modelos explicativos de maior consistência. $\mathrm{O}$ caráter em aberto do processo permite o surgimento de diversas possibilidades conceituais, que vão sendo refinadas tendo o próprio campo empírico como ponto de partida para a seletividade.

Este artigo tentou atacar um aspecto bastante problemático para qualquer pesquisador que pretende utilizar a GT: entender as características e implicações das três abordagens que se apresentam na literatura. Tendo em vista que compreender a natureza que as distingue, torna-se essencial para uma aplicação coerente aos propósitos de um estudo. Discutiu-se, portanto, como as questões paradigmáticas estavam intrincadas com as divergências entre os modelos propostos. A GT clássica ou glaseriana cujos pressupostos ontológicos e epistemológicos assentam-se ao positivismo tradicional pela crença na realidade externa e na capacidade de captura dos fenômenos humanos por meio de um empirismo e um indutivismo que remontam aos moldes das ciências naturais. A GT de Strauss e Corbin que marcadas pelo tom 
prescritivo e didático reconhecem em seus procedimentos apenas uma possibilidade de aproximação do fenômeno, mas que ainda exibe traços de uma postura objetivista em que pesquisador e participantes, e por isso, relacionada ao pós-positivismo. E por fim, a GT construtivista de Charmaz, que se propõe a uma releitura das estratégias do método, sugerindo o uso flexível de seu modelo sistemático para as pesquisas interpretativistas.

Ao expor as crenças e pressupostos que, de forma implícita ou não, perpassam as abordagens da GT não se pretendeu atribuir qual visão seria a mais adequada, já que não há uma versão certa ou errada, uma vez que representam visões de mundo distintas. A ciência desses elementos visa dá suporte aos estudiosos, quando da opção metodológica cujos critérios repousam na natureza e no problema da investigação empreendida. Não obstante, esta breve explanação sobre o tema levantou questões para reflexão, apontando pontos de ambiguidade presentes no método, em suas bases teóricas e em seus fundamentos lógicos. Entende-se que a GT tem se desenvolvido, embora à custa de divergências, seu aparato metodológico tem se demonstrado usual e pertinente a diversas áreas do conhecimento. Em virtude da originalidade e da versatilidade de seu modelo, é que se advoga em favor de ambas as práticas - objetivistas, mas sobretudo, subjetivistas - em virtude do crescente que os estudos interpretativistas têm vivenciado nas últimas décadas, marcando uma nova fase no fazer científico.

A área de Administração pode ser grande beneficiada da GT sobretudo quanto ao seu flexível, já que tem o método de estudo de caso uma prática de pesquisa bastante difundida. $\mathrm{O}$ levantamento nos anais do EnPQ, no entanto, apontou um debate pouco expressivo do tema, conformou foi identificado. Estudos futuros poderiam replicar o levantamento em bases maiores e verificar o status do tema, principalmente em publicações permanentes. Novas investigações poderiam também aprofundar o uso flexível da GT especificamente nos métodos de estudo de caso qualitativo e gerar novos entendimentos sobre efeito na qualidade dos resultados.

\section{REFERÊNCIAS}

BANDEIRA-DE-MELLO, R.; CUNHA, C. A. Grounded theory. In: GODOI, C. K.; BANDEIRA-DE-MELLO, R.; SILVA, A. B. (Org.). Pesquisa qualitativa em estudos organizacionais: paradigmas, estratégias e métodos. São Paulo: Saraiva, 2006. cap. 8, p. 241-266.

BARDIN. L. Análise de conteúdo (L. A., Reto \& A. Pinheiro, Trad.). Lisboa: Edições 7o. Livraria Canuto, 2004.

BAUER, M. W.; AARTS, B. A construção do corpus: um princípio para a coleta de dados qualitativos. In Bauer, $\mathrm{M}$. W., \& Gaskell, G. (Ed.). Pesquisa qualitativa com texto, imagem e som: um manual prático. Petrópolis, RJ: Vozes, 2008. 
BERBER Sardinha, T. Linguística de Corpus.

São Paulo: Manole, 2004.

BLACK, N. M. Blood money: a grounded theory of corporate citizenship, Myanmar (Burma) as a case in point. 2009. 551f. Tese (Doctor of philosophy in strategic management) - The University of Waikato, Te Waananga o Waikato. 2009.

BRYANT, A. A Constructivist response to Glaser. Forum: Qualitative Social Research. v. 4, n. 1, 2003.

BRYANT, A. Grounded theory and pragmatism: The curious case of Anselm Strauss. Forum: Qualitative Social Research. v.10, n. 3, art 2, set. 2009.

CALIN, M.; WEISS, S. What is grounded theory? ETH. University of St. Gallen. Nov. 2011. Disponível em: <www.tim.ethz.ch> Acesso em: 15 out. 2012.

CHARMAZ, K. Grounded theory: objectivist and constructivist methods. In: DENZIN, N. K.; LINCOLN, Y. S. (Eds.). Strategies of qualitative inquiry. 2 ed. London: Sage Publications Limited, 2003. p. 249-291.

CHIZZOTTI, A. A pesquisa qualitativa em ciências humanas e sociais: evolução e desafios. Revista Portuguesa de Educação, Braga, v.16, n. 2, p. 221-236, 2003.

FLICK, U. Uma introdução à pesquisa qualitativa. Tradução de Sandra Netz. 2. ed. Porto Alegre: Bookman, 2004.

GLASER, B. G. Basics of grounded theory analysis. Mill Valley, CA: Sociology Press, 1992.

GLASER, B. G.; STRAUSS, A. L. The discovery of grounded theory: strategies for qualitative research. London: Aldine Transaction, 1967.

GUBA, E. G.; LINCOLN, Y. S. Competing paradigms in qualitative research. In: DENZIN, N. K.; LINCOLN, Y. S. (Eds.). Handbook of qualitative research. Thousand Oaks, CA: Sage, 1994. p. 105-117.

KELLE, U. Hacer "emerger" o "forzar" los datos empíricos? Forum: Qualitative Social Research. v.6, n. 2, 2005.

MAINES, D. R. Interactionism and practice. Applied Behavioral Science Review, v. 5, n. 1, p.1-8, 1997.

MERRIAN, S. B. Qualitative research: case study, applications in education. San Francisco: Jossey-Bass, 2009. 304p. 
MILLS, J.; BONNER, A.; FRANCIS, K. The development of constructivist grounded theory. International journal of qualitative methods, v. 5, n. 1, 2006.

NELSON, L. D. Herbert Blumer's Symbolic Interactionism. University of Colorado, 1998. Disponível em: $<$ http://www.colorado.edu/communication/ meta-discourses>. Acesso em: 20 jun 2012.

SCHWANDT, T. A. Constructivist, interpretivist approaches to human inquiry. In: DENZIN, N. K.; LINCOLN, Y. S. (Eds). Handbook of qualitative research. Thousand Oaks, CA: Sage Publications, 1994. p. 118-137 STRAUSS, A. L.; CORBIN, J. Basics of qualitative research: grounded theory procedures and techniques. 2 ed. Thousand Oaks, CA: Sage, 1998.

WESTWOOD, J. The marketing plan workbook. New York: Ingram Pub Services, 2005. 